University of Nebraska - Lincoln

DigitalCommons@University of Nebraska - Lincoln

Faculty Publications from the Harold W. Manter Laboratory of Parasitology

2009

SYSTEMATIC POSITION OF PSEUDOCORYNOSOMA AND ANDRACANTHA (ACANTHOCEPHALA, POLYMORPHIDAE) BASED ON NUCLEAR AND MITOCHONDRIAL GENE SEQUENCES

Martín García-Varela

Universidad Nacional Autónoma de México

Follow this and additional works at: https://digitalcommons.unl.edu/parasitologyfacpubs

Part of the Parasitology Commons

García-Varela, Martín, "SYSTEMATIC POSITION OF PSEUDOCORYNOSOMA AND ANDRACANTHA (ACANTHOCEPHALA, POLYMORPHIDAE) BASED ON NUCLEAR AND MITOCHONDRIAL GENE SEQUENCES" (2009). Faculty Publications from the Harold W. Manter Laboratory of Parasitology. 716. https://digitalcommons.unl.edu/parasitologyfacpubs/716

This Article is brought to you for free and open access by the Parasitology, Harold W. Manter Laboratory of at DigitalCommons@University of Nebraska - Lincoln. It has been accepted for inclusion in Faculty Publications from the Harold W. Manter Laboratory of Parasitology by an authorized administrator of DigitalCommons@University of Nebraska - Lincoln. 


\title{
SYSTEMATIC POSITION OF PSEUDOCORYNOSOMA AND ANDRACANTHA (ACANTHOCEPHALA, POLYMORPHIDAE) BASED ON NUCLEAR AND MITOCHONDRIAL GENE SEQUENCES
}

\author{
Martín García-Varela, Gerardo Pérez-Ponce de León, Francisco J. Aznar, and Steven A. Nadler† \\ Departamento de Zoología, Instituto de Biología, Universidad Nacional Autónoma de México, Avenida Universidad 3000; Ciudad Universitaria; \\ C.P. 04510, Mexico City, D.F. e-mail: garciav@servidor.unam.mx
}

\begin{abstract}
Species of Pseudocorynosoma are North and South American acanthocephalans that use waterfowl as definitive hosts and amphipods as intermediate hosts, whereas species of Andracantha occur in fish-eating birds with a worldwide distribution. Pseudocorynosoma and Andracantha were originally described as Corynosoma (now restricted to endoparasites of marine mammals). Morphologically, Andracantha is distinct from other genera of Polymorphidae in possessing 2 fields of spines on the trunk, whereas Corynosoma and Pseudocorynosoma have a single field. A recent phylogenetic hypothesis based on morphological characters suggested that Andracantha is closely related to Corynosoma, whereas Pseudocorynosoma was of uncertain phylogenetic position within the Polymorphidae. To test the systematic affinities of these 3 genera, we sequenced 2 nuclear genes (SSU and LSU ribosomal DNA) and 1 mitochondrial gene (cytochrome $c$ oxidase subunit 1; cox 1) of species representing Corynosoma, Andracantha, and Pseudocorynosoma and analyzed the data, including available sequences of other polymorphids. Maximum parsimony (MP), maximum likelihood (ML), and Bayesian analyses of the combined (SSU + LSU) sequences and the concatenated data of 3 genes (SSU + LSU + cox 1) placed Andracantha as the sister taxon to Corynosoma with robust support values. All analyses also showed that Pseudocorynosoma is an independent lineage that does not share a common ancestry with Andracantha and Corynosoma. These phylogenetic hypotheses suggest that birds were the ancestral hosts of polymorphids and that the association of Corynosoma with marine mammals represents a subsequent episode of colonization.
\end{abstract}

Adult polymorphid acanthocephalans are intestinal parasites of marine mammals, fish-eating birds, and waterfowl. Their life cycles typically include a crustacean (amphipod, copepod, or decapod) as intermediate host and may include fish, snakes, frogs, or toads as paratenic hosts (Schmidt, 1985; Hoberg, 1986; Pichelin et al., 1998; Nickol et al., 1999, 2002). The systematics of this family at the generic level have been unstable for decades. Schmidt (1973) considered 8 valid genera, including Southwellina Witenberg, 1932, which this author resurrected after a long period in which it had been considered as synonymous with Arhythmorhynchus Lühe, 1911. Later, Schmidt (1975) erected Andracantha, including 3 species classified previously as members of Corynosoma Lühe, 1904. More recently, Nickol et al. (1999) reintroduced Profilicollis Meyer, 1931, as a valid genus; it had previously been considered as a subgenus of Polymorphus Lühe, 1911. Finally, Aznar et al. (2006) erected Pseudocorynosoma Aznar, Pérez-Ponce de León, and Raga, 2006, to reallocate several species previously included in Corynosoma.

Pseudocorynosoma currently comprises 5 species that use waterfowl as definitive hosts and amphipods as intermediate hosts, with distributions ranging from North America to South America (Van Cleave, 1945; Podesta and Holmes, 1970; Farias and Canaris, 1986). The 5 species of Pseudocorynosoma were originally assigned to Corynosoma Lühe, 1904; however, Aznar et al. (2006) clearly demonstrated morphological and ecological differences among species of Corynosoma and Pseudocorynosoma. As currently defined, Corynosoma constitutes a monophyletic assemblage of species with a worldwide distribution that occur as adults in hosts from the marine environment (mainly pinnipeds); they use marine amphipods as intermediate

Received 28 November 2007; revised 10 May 2008; accepted 10 June 2008.

* Departamento de Biología Animal, Instituto Cavanilles de Biodiversidad y Biología Evolutiva, Universitat de Valencia, Burjasot, Valencia, Spain.

$\dagger$ Department of Nematology, University of California, Davis, California $95616-8668$ hosts and teleosts as paratenic hosts (Belopolskaja, 1958; Golvan, 1959; Zdzitowiecki, 1985; Aznar et al., 1999, 2006). Another genus proposed to have systematic affinities to Corynosoma is Andracantha Schmidt, 1975, which currently includes 7 species that occur in piscivorous birds, mainly shags and cormorants. Six of the 7 known species of Andracantha were formerly included in Corynosoma (Aznar et al., 2006; Monteiro, et al., 2006). The main diagnostic trait of Andracantha is the possession of 2 fields of spines on the trunk; both Corynosoma and Pseudocorynosoma have 1 field. Aznar et al. (2006) analyzed 15 morphological characters and ecological traits among Andracantha, Corynosoma, Pseudocorynosoma, and other polymorphids to infer the phylogenetic relationships among these taxa. Their analysis suggested a close (but weakly supported) relationship between Andracantha and Corynosoma. Similarly, taxa now recognized as a distinct genus (Pseudocorynosoma) were monophyletic, but with unreliable (56\%) bootstrap support. Nevertheless, this result was used to support the establishment of Pseudocorynosoma as a separate genus, since these authors (Aznar et al., 2006) provided additional information on host-parasite relationships and a detailed comparison of foretrunk musculature.

The main objective of the present research was to obtain molecular sequence data to test relationships among these genera. This was accomplished by using data from 2 nuclear genes (SSU and LSU ribosomal DNA) and 1 mitochondrial gene (cox 1) for representative species of Corynosoma, Andracantha, and Pseudocorynosoma in the broader context of other polymorphid genera (including Polymorphus, Profilicollis, Southwellina, and Hexaglandula Petrochenko, 1950).

\section{MATERIALS AND METHODS}

\section{Specimens and DNA isolation}

Acanthocephalans were collected from vertebrate and invertebrate hosts. Worms were washed 3 times in $0.9 \%(\mathrm{w} / \mathrm{v})$ saline, preserved in absolute ethanol, and stored at $4 \mathrm{C}$. For taxonomic identification, some specimens of most species were stained with Meyer's paracarmine, cleared with methyl salicylate, and mounted on permanent slides using 
TABLE I. Specimen information and GenBank accession numbers for specimens studied in this work.

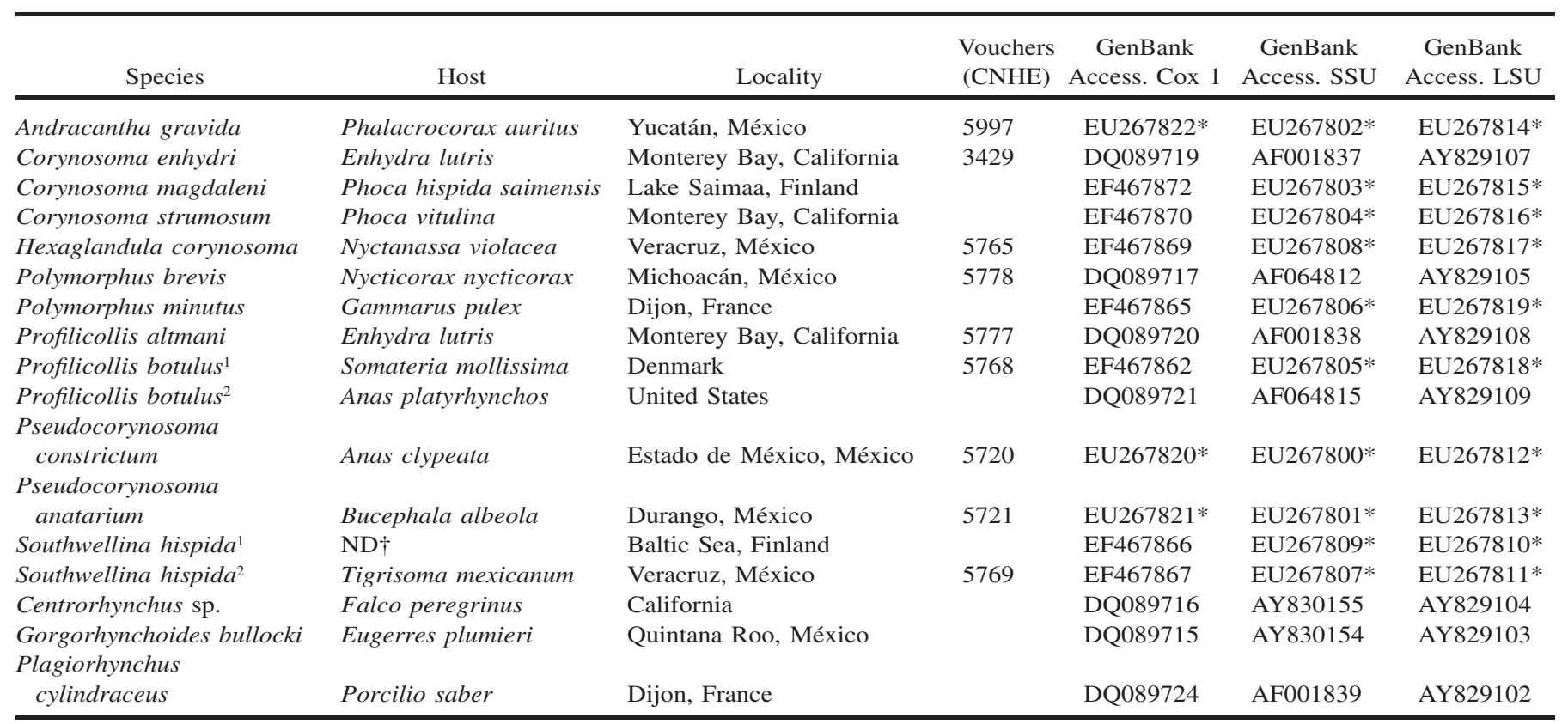

* Sequences marked with an asterisk were obtained in this study.

$\dagger \mathrm{ND}$, not determined.

Canada balsam. The acanthocephalans were identified by conventional morphological criteria following the keys of Yamaguti (1963), Petrochenko (1958), and Schmidt (1973). In addition, original and revised descriptions of the species (e.g., Van Cleave, 1945; Schmidt, 1975) were consulted as needed. Avian definitive hosts were identified using field guides by Howell and Webb (1995) and the American Ornithologists' Union (1998). Voucher specimens were deposited at the Colección Nacional de Helmintos, Instituto de Biología, UNAM, México City, México (accession numbers shown in Table I).

\section{Amplification and sequencing of DNA}

A single specimen of each species was digested overnight at $56 \mathrm{C}$ in a solution containing $10 \mathrm{mM}$ Tris $-\mathrm{HCl}(\mathrm{pH} 7.6), 20 \mathrm{mM} \mathrm{NaCl}, 100 \mathrm{mM}$ $\mathrm{Na}_{2}$ EDTA (pH 8.0), $1 \%$ Sarkosyl, and $0.1 \mathrm{mg} / \mathrm{ml}$ proteinase K. Following the digestion, DNA was extracted from the supernatant using the DNAzol reagent (Molecular Research Center, Cincinnati, Ohio) according to the manufacturer's instructions.

Two regions of nuclear ribosomal DNA (rDNA) were amplified, using the polymerase chain reaction (PCR). The near-complete SSU rDNA $(\sim 1,800 \mathrm{bp})$ was amplified in 1 fragment, using the forward primer 5'-AGATTAAGCCATGCATGCGT and reverse primer 5'-GCA GGTTCACCTACGGAAA (Garey et al., 1996). The near-complete LSU rDNA $(\sim 2,900 \mathrm{bp})$ was amplified using 2 overlapping PCR fragments of 1,400-1,500 bp. Primers for LSU amplicon 1 were forward 5'-CAAGTACCGTGAGGGAAAGTTGC and reverse 5'-CTTCTCCA AC(T/G)TCAGTCTTCAA; amplicon 2, forward 5'-CTAAGGAGTGT GTAACAACTCACC and reverse 5'-CTTCGCAATGATAGGAAGAG CC (García-Varela and Nadler, 2005). A partial (661 bp) sequence of mitochondrial cytochrome cox 1 was amplified using the forward primer 5'-AGTTCTAATCATAA(R)GATAT(Y)GG and reverse 5'-TAAAC TTCAGGGTGACCAAAAAATCA (Folmer et al., 1994).

PCR reactions $(25 \mu \mathrm{l})$ consisted of $10 \mu \mathrm{M}$ of each primer, $2.5 \mu \mathrm{l}$ of $10 \times$ buffer, $2 \mathrm{mM}$ of $\mathrm{MgCl}_{2}$, and $1 \mathrm{U}$ of Taq DNA polymerase (Platinum Taq, Invitrogen Corporation, São Paulo, Brazil). PCR cycling parameters for rDNA amplifications included denaturation at $94 \mathrm{C}$ for 3 min, followed by 35 cycles of $94 \mathrm{C}$ for $1 \mathrm{~min}$, annealing at 50-58 C (optimized for each rDNA amplification) for $1 \mathrm{~min}$, and extension at $72 \mathrm{C}$ for $1 \mathrm{~min}$, followed by a postamplification incubation at $72 \mathrm{C}$ for 7 min. PCR cycling conditions for the cox 1 amplifications included denaturation at $94 \mathrm{C}$ for $5 \mathrm{~min}$, followed by 35 cycles of $94 \mathrm{C}$ for 1 min, annealing at $40 \mathrm{C}$ for $1 \mathrm{~min}$, and extension at $72 \mathrm{C}$ for $1 \mathrm{~min}$, followed by a postamplification incubation at $72 \mathrm{C}$ for $5 \mathrm{~min}$.

Each PCR product was purified using Millipore columns (Amicon, Billerica, Massachusetts). Purified products were cloned by ligation into pGEM-T vector (Promega, Madison, Wisconsin) and used to transform competent Escherichia coli (JM109). Positive clones were identified by blue/white selection, and clone (insert) size was confirmed by PCR of DNA extracts prepared from bacterial (clone) colonies. Liquid cultures for minipreps were grown in Luria broth containing $50 \mu \mathrm{g} / \mathrm{ml}$ of ampicillin. Plasmids for DNA sequencing were prepared using commercial miniprep kits (Qiaprep, Qiagen, Valencia, California). Plasmids were sequenced for both DNA strands using universal (vector) and internal primers. Sequencing reactions were performed using ABI Big Dye (Applied Biosystems, Boston, Massachusetts) terminator sequencing chemistry, and reaction products were separated and detected using an ABI 3730 capillary DNA sequencer. Contigs were assembled and base-calling differences were resolved using Codoncode Aligner version 1.4.5 (Codoncode Corporation, Dedham, Massachusetts). All sequences have been deposited in the GenBank database (accession numbers shown in Table I).

\section{Alignments and phylogenetic analyses}

The SSU and LSU data sets were aligned separately using ProAlign version 0.5 (Loytynoja and Milinkovitch, 2003). For each alignment, a ProAlign guide tree was constructed using corrected (for multiple hits) pair-wise distances; this guide tree was used to estimate the hidden Markov model parameters $(\delta$ and $\varepsilon$ ) for progressive multiple alignment. Program (Java) memory and band-width were increased as required to complete the alignment. The minimum posterior probability of sites was used as the criterion for detecting and removing unreliably aligned sequences. To reduce the likelihood of excluding correctly aligned sites, the filter threshold was set to $60 \%$ minimum posterior probability. For the SSU sequences, using ProAlign to detect and remove unreliably aligned sequences by their posterior probabilities excluded 211 of 1,746 sites. For the LSU dataset, 666 of 2,981 sites were excluded based on posterior probability filtering. Thus, following removal of unreliably aligned sites, these combined rDNA datasets included 3,850 characters. Sequences from the mitochondrial protein coding gene cox 1 were 655 bp in all taxa. These nucleotide sequences were readily aligned based on their inferred (translated) cox 1 protein sequences. The concatenated 
3-gene dataset included 4,505 characters (filtered rDNA alignments plus cox 1 sequences).

\section{Phylogenetic analyses}

The SSU and LSU rDNA filtered alignments were combined and analyzed as 1 rDNA dataset because these genes represent a single nuclear locus. A concatenated dataset including all 3 genes (SSU, LSU, and cox 1) was analyzed separately. MP and ML trees were inferred using PAUP* 4.0b10 (Swofford, 2002). For ML analyses, the Akaike Information Criterion (AIC) was used to assess the fit of GTR (General Time Reversible) nucleotide substitution models for these data (Rodríguez et al., 1990) as implemented using Modeltest version 3.0 (Posada and Crandall, 1998). The best-fit substitution model for SSU and LSU (both as evaluated separately and as a combined dataset) was GTR + $\mathrm{I}+\mathrm{G}$, the best-fit model for cox 1 was K81uf $+\mathrm{I}+\mathrm{G}$, and for the concatenated 3-gene dataset, the best-fit model was GTR + I + G. For phylogenetic analysis, this GTR model with invariable sites $(+I)$ and rate heterogeneity $(+\mathrm{G})$ (Yang, 1994) was used for rDNA and concatenated datasets, but with different estimated parameters for each as determined by Modeltest. Tree searches were performed using 100 (ML) and 1,000 (MP) random taxon addition heuristic searches with treebisection-reconnection branch swapping. Clade support was assessed by bootstrap resampling with 10,000 (MP) or 1,000 (ML) bootstrap pseudoreplicates. MrBayes v3.0b4 (Huelsenbeck and Ronquist, 2001) was used to analyze the concatenated data set, sampling every 5,000 trees over 5,000,000 generations (burn-in determined empirically). For this analysis, a character partition corresponding to the 3 loci (nuclear SSU, LSU, and mitochondrial cox 1) was invoked, and the parameters of the likelihood model were set to the GTR (SSU, LSU partitions) and K81 (cox 1 partition) substitution models with the invgamma option (a proportion of sites are invariable, with the remaining sites modeled by a gamma distribution of rate variability). The priors for the proportion of invariable sites (pinvarpr) were fixed separately for each partition, with the values estimated by Modeltest ( pinvarpr $=0.4156$ for SSU, pinvarpr $=0.3945$ for LSU, and pinvarpr $=0.3443$ for cox 1 ).

To compare trees representing specific alternative phylogenetic hypotheses, topological constraints were defined on trees obtained from MP and ML analyses of the concatenated (SSU + LSU + cox 1) dataset. Differences between unconstrained (best) and constrained trees representing alternative hypotheses were evaluated using the Shimodaira and Hasegawa likelihood test (Shimodaira and Hasegawa, 1999) and Templeton's modified parsimony test (Templeton, 1983) as executed in PAUP*. Trees were drawn using RETREE and DRAWGRAM from PHYLIP (Felsenstein, 1999). The observed (uncorrected) genetic differentiation between taxa was represented using the uncorrected (p-distance) method on the filtered concatenated dataset. Alignments and tree files have been deposited in TreeBASE (Sanderson et al., 1994).

\section{RESULTS}

\section{SSU + LSU dataset}

The combined (SSU + LSU) rDNA dataset included 17 taxa, with 3,850 sites and 495 parsimony informative characters. MP analysis of this dataset yielded 3 trees, with a C.I. $=0.73$ and length of 1,877 steps. The MP consensus tree (Fig. 1) supported the monophyly of Polymorphidae. This tree was composed of 4 main clades. The first clade contained 2 species of Profilicollis + Polymorphus minutus Goeze, 1782 and was strongly supported $(100 \%)$ by bootstrap resampling. The second clade included the only sampled representative of Hexaglandula, plus 2 isolates of S. hispida Van Cleave, 1925 and Polymorphus brevis, Van Cleave, 1916. However, only the sister-group relationship between the $S$. hispida isolates and the clade consisting of $P$. brevis plus Southwellina received reliable bootstrap support. The third clade was composed of 2 species representing Pseudocorynosoma and had a bootstrap value of $100 \%$. The fourth clade was composed of species representing Andracantha and Corynosoma and had $100 \%$ bootstrap support; however, a polytomy was recovered that included Pseudocorynosoma and Andracantha + Corynosoma, so this analysis did not resolve relationships among all 3 genera (Fig. 1). ML analysis of the combined nuclear rDNA yielded 1 tree (Fig. 2). This ML tree was fully resolved and yielded 4 clades with the same clade composition as the MP trees, except for the position of Pseudocorynosoma. Each of these 4 clades also received strong ML bootstrap support (Fig. 2). Relationships among these 4 clades differed between MP and ML methods; however, these amongclade differences were not reliably supported, as assessed by bootstrap resampling for ML or MP inference.

\section{Combined SSU + LSU + cox 1 dataset}

The concatenated dataset of 3 genes consisted of 4,505 sites, with 806 parsimony informative characters. MP analysis of these SSU + LSU + cox 1 data yielded a single tree with a C.I. $=0.60$ and length of 3,290 steps. This tree (Fig. 3) had the same general topology as the combined SSU + LSU MP analysis (Fig. 1), but had more resolved nodes and higher bootstrap values for clades (Fig. 3). The ML analysis of the concatenated dataset yielded a single tree (Fig. 4) showing the same topology as the ML tree for the combined SSU + LSU analysis (Fig. 2). Bootstrap support was higher for certain clades in the concatenated ML tree. Bayesian analysis of the concatenated dataset also depicted these same relationships among genera as ML trees for the combined and concatenated datasets. However, Bayesian posterior probabilities (BPP) of clades were much higher than bootstrap values, suggesting that relationships among all genera were well resolved in the sampled posterior probability distribution (Fig. 4).

\section{DISCUSSION}

The MP, ML, and Bayesian analyses of the combined rDNA $(\mathrm{SSU}+\mathrm{LSU})$ and concatenated dataset of 3 genes showed that Polymorphidae is a monophyletic assemblage, and this result is strongly supported by bootstrap resampling and Bayesian posterior probabilities. These phylogenetic analyses included 3 of the 30 species of Corynosoma considered valid by Aznar et al. (2006), including the type species Corynosoma strumosum $\mathrm{Ru}-$ dolphi, 1802. Corynosoma was recovered as monophyletic with high bootstrap values and BPP. These results are congruent with those of previous studies based on morphological and molecular data, which support the monophyly of Corynosoma spp. (García-Varela et al., 2005; Aznar et al., 2006).

Andracantha is composed of 7 species parasitizing shags, cormorants, and other piscivorous birds (Monteiro et al., 2006). The only diagnostic morphological difference between Andracantha and Corynosoma is the possession of spines in 2 fields of the trunk in the former. Based on this morphological feature, Schmidt (1975) transferred 3 species of Corynosoma (C. gravida Alegret, 1941, C. mergi Lundström, 1941, and C. phalacrocoracis Yamaguti, 1939) to Andracantha. In the present study, we used sequences of the type species, A. gravida. The MP, ML, and Bayesian trees derived from the rDNA and concatenated datasets placed Andracantha as the sister taxon of Corynosoma, with strong support as assessed by bootstrap resampling and Bayesian posteriors. This topological result is not inconsistent with generic status for Andracantha, but neither does it provide topological evidence for recognition of Andra- 


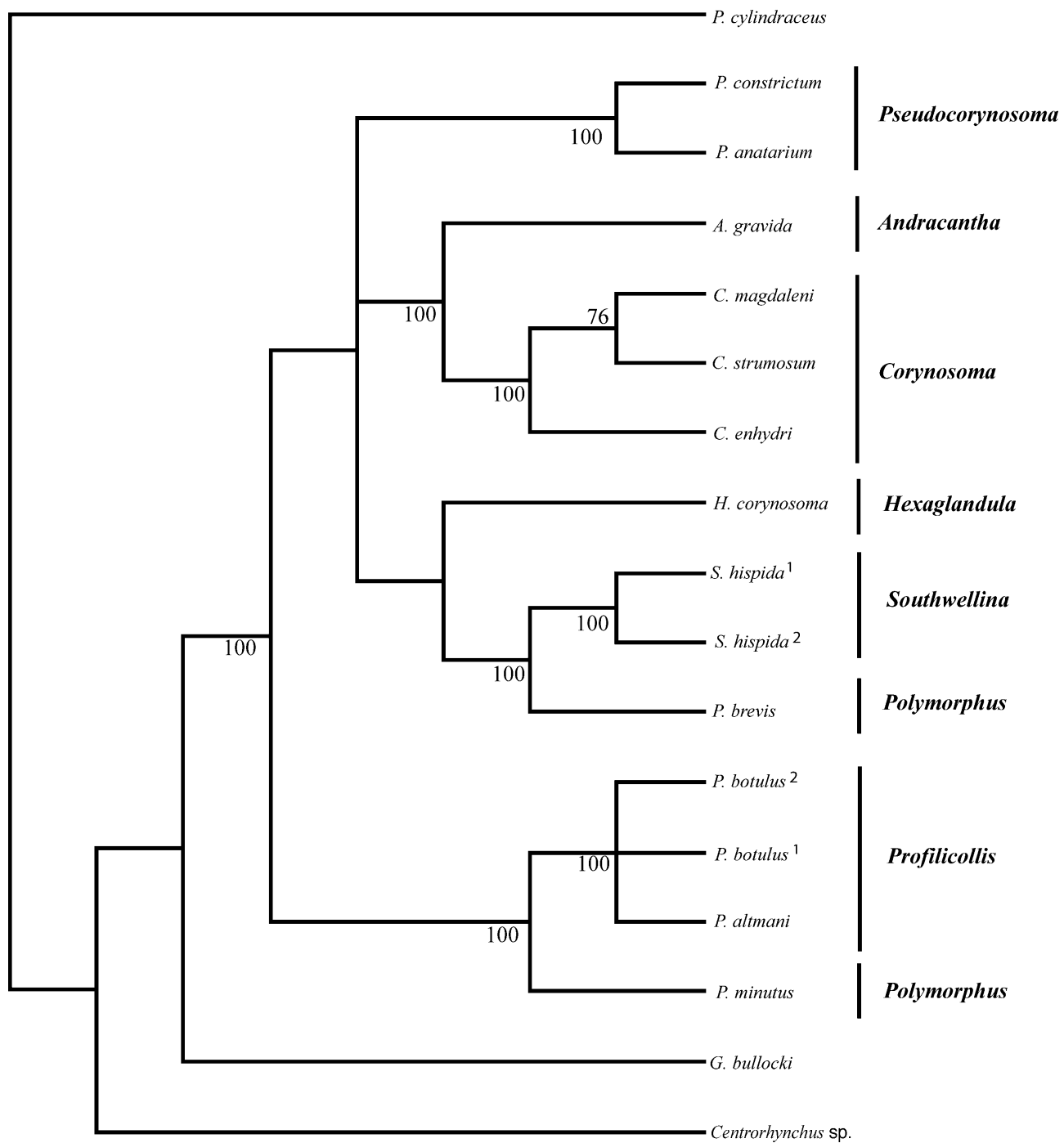

FIGURE 1. Strict consensus of 3 equally parsimonious trees (1,877 steps) inferred for the combined SSU + LSU rDNA dataset. Numbers below internal nodes show MP bootstrap clade frequencies.

cantha as separate from Corynosoma. However, the genetic divergence (estimated from the filtered concatenated dataset) between Andracantha and Corynosoma is 5\%; this divergence value is similar to those representing inter-generic comparisons in Polymorphidae, i.e., P. minutus, + Profilicollis and P. brevis + Southwellina is $5 \%$, lending support to the hypothesis of Andracantha as a distinct genus. The inclusion of more congeners in the molecular analysis is necessary to more fully test this notion. The phylogenetic pattern obtained in this study is also congruent with previous analyses based on morphological and ecological data, where Andracantha was closely related to Corynosoma. The known life cycles of both genera involve marine fish as paratenic hosts (see Aznar et al., 2006). Since both pinnipeds (definitive hosts of Corynosoma) and cormorants (definitive hosts of Andracantha) feed on fish, opportunities for host-switching of polymorphids between definitive hosts might have been frequent (Hoberg and Adams, 2000; Aznar et al., 2006).

The type species of Pseudocorynosoma was originally described as Corynosoma constrictum, Van Cleave 1918, for spec- imens obtained from an American scoter or possibly of a surf scoter from Yellowstone Park, Wyoming (Van Cleave, 1945). Subsequently, 4 additional species from waterfowl were added to the genus $(P$. peposacae Porta, $1914 ; P$. anatarium Van Cleave 1945; $P$. enrietti Molfi and Fernandes, 1953; and $P$. inheringi Machado Filho, 1961). Moreover, another 2 species, C. longilemniscatus Machado Filho, 1961, and C. molfifernandesi Machado Filho, 1962, were described and recently were considered as synonyms of $P$. peposacae and $P$. enrietti, respectively (Aznar et al., 2006). Based on a phylogenetic analysis of 15 morphological characters, comparative analysis of trunk musculature, and data derived from host-parasite associations of 7 species of Corynosoma from marine mammals and 4 species from waterfowl, Aznar et al. (2006) suggested that the species from freshwater waterfowl belonged to a distinct genus, Pseudocorynosoma. In the present study, we analyzed 2 species of parasites representing Pseudocorynosoma, including the type species $P$. constrictum. The genetic distance between $P$. constrictum and $P$. anatarium is $3 \%$; this level of divergence is similar to that of other congeneric comparisons, for example, 


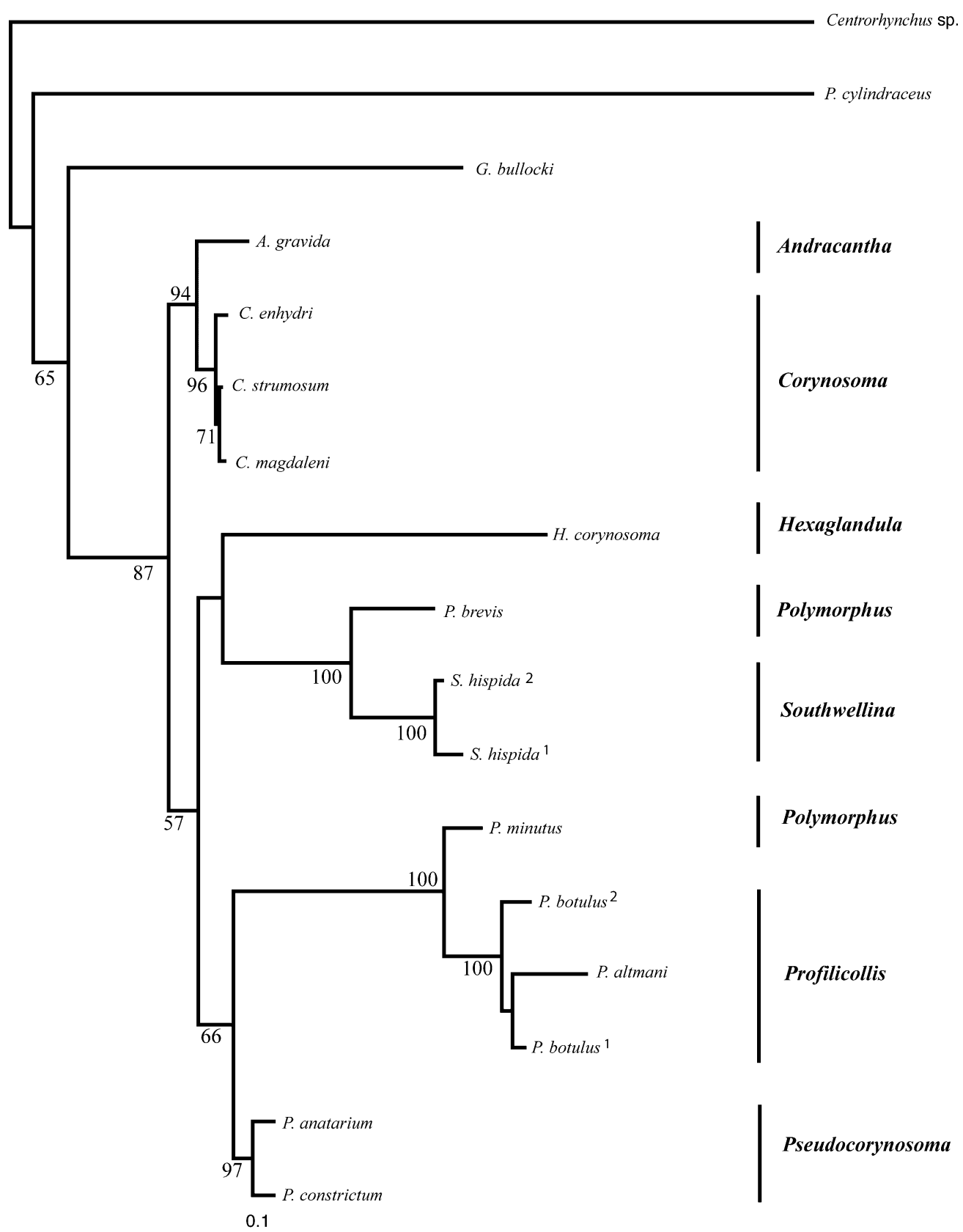

FIGURE 2. ML tree (-ln likelihood 14,475.67) inferred from combined SSU + LSU rDNA dataset. Numbers near internal nodes show ML bootstrap clade frequencies.

among species of Corynosoma (0.7-2\%) and species of Profilicollis (up to 4\%). The 2 species of Pseudocorynosoma were recovered as a monophyletic group, consistent with its recognition as a separate genus. However, to test the taxonomic validity of Pseudocorynosoma, the alternative hypothesis of ( $\mathrm{An}$ dracantha (Corynosoma, Pseudocorynosoma)) was evaluated with MP and ML analyses using the concatenated dataset of 3 genes. The constrained analyses of MP and ML showed a tree with a length of 3,331 steps and $-\ln =21,324.60$, respectively, whereas original hypotheses of MP and ML yielded a tree with a length of 3,290 and $-\ln =21,129.49$, respectively. Based on both the Shimodaira and Hasegawa (1999) likelihood test and
Templeton's (1983) parsimony test as executed in PAUP*, the alternative hypotheses of Pseudocorynosoma as the sister group of Corynosoma is significantly worse than the best trees represented in Figures 3 and 4.

The phylogenetic position of Pseudocorynosoma within Polymorphidae varies depending on the inference method. The MP trees derived from the concatenated dataset yielded the topology: (Pseudocorynosoma ((Andracantha, Corynosoma), (Hexaglandula (Southwellina, P. brevis)))), whereas the ML and Bayesian analyses (rDNA and concatenated) differed, yielding (Pseudocorynosoma (P. minutus, Profilicollis)). Aznar et al. (2006) indicated that species of Pseudocorynosoma are nearly 


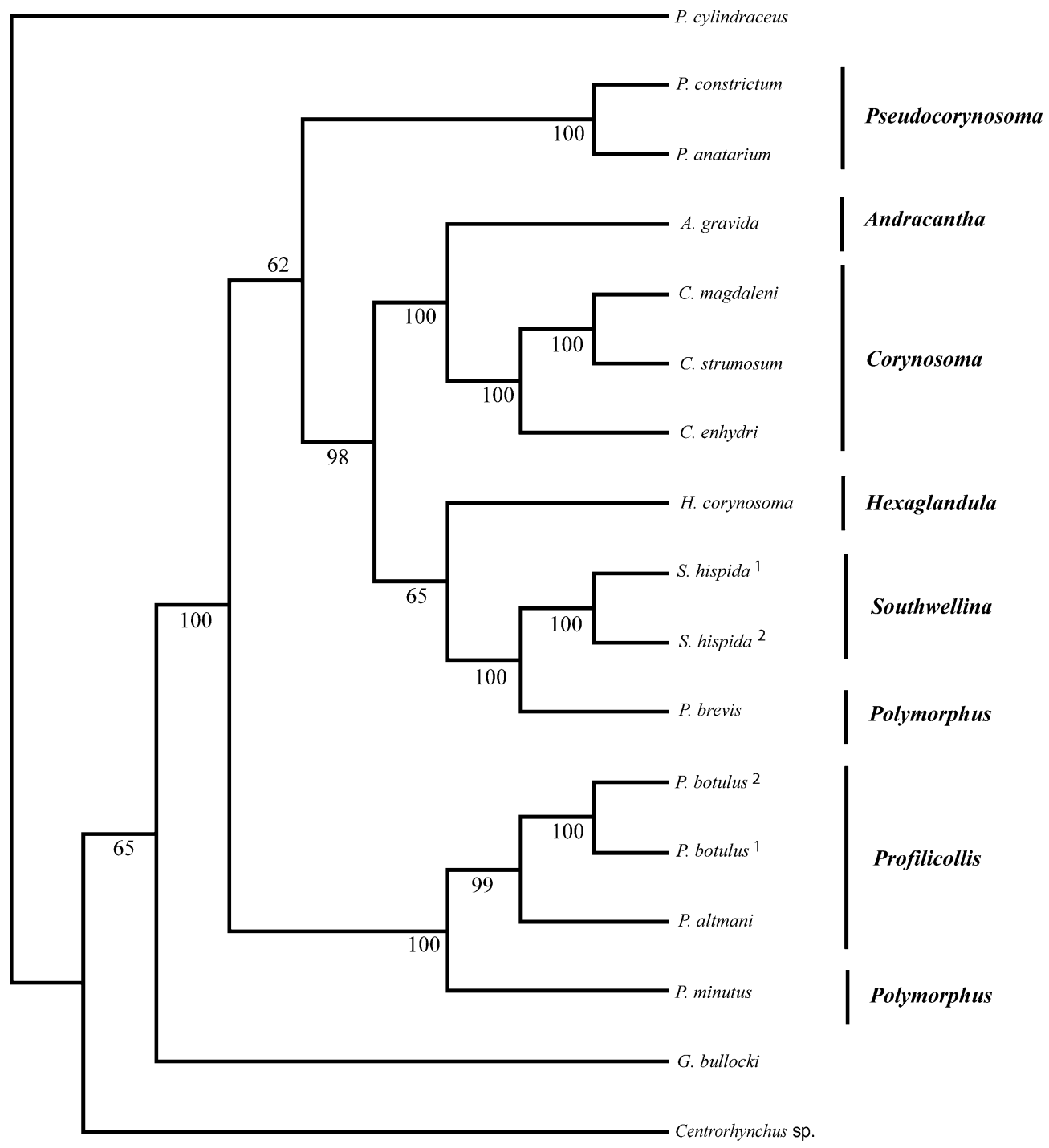

FiguRE 3. MP tree (3,290 steps) inferred from the concatenated SSU + LSU + cox 1 dataset. Numbers below internal nodes show MP bootstrap clade frequencies.

identical to Polymorphus with respect to morphology and life cycle. Indeed, only the possession of genital spines as an isolated field, at least in males, and 6 cement glands in some species allows Pseudocorynosoma to be separated from Polymorphus. It is important to note that the other species of Polymorphus included in the analysis, P. brevis, and P. minutus, are paraphyletic in all analyses. An alternative topology test (Shimodaira-Hasegawa) showed that the monophyly of Polymorphus was a significantly worse interpretation (result not shown) of the concatenated (SSU $+\mathrm{LSU}+\operatorname{cox} 1)$ data than the tree shown in Fig. 4. Therefore, the appropriate generic designation for Polymorphus taxa requires further consideration (see Amin, 1992).

The Polymorphidae is composed of an assemblage of genera with a long history of conflicting status. The taxonomic position among some representatives has been tested using either morphological (Aznar et al., 2006) or molecular (García-Varela and Pérez-Ponce de León, 2008) characters. However, the present study represents the first phylogenetic analysis that includes a more complete representation of the family (7 of 10 genera), thereby providing a better phylogenetic framework to infer the evolution of host-parasite associations. Parsimony mapping of definitive host associations onto MP, ML, and Bayesian trees indicates that birds were the ancestral hosts of polymorphids, and the association of Corynosoma with marine mammals would represent a subsequent episode of colonization. Sampling of Bolbosoma, Arythmorhynchus, and Diplospinifer are fundamental to providing a comprehensive phylogenetic framework for this family and to provide additional tests of the hypotheses discussed herein.

\section{ACKNOWLEDGMENTS}

We are grateful to Patricia de la Torre and Laura Marquez for their help with the molecular techniques. This research was supported by the Programa de Apoyo a Proyectos de Investigación e Inovación Tecnológica (PAPIIT No. 206906) and the Consejo Nacional de Ciencia y Tecnología, through program Apoyo Complementario a Investigadores en Proceso de Consolidación (CONACYT-No. 52185) and by the project CGL2007-63221 of the Ministry of Education and Science (MEC) 


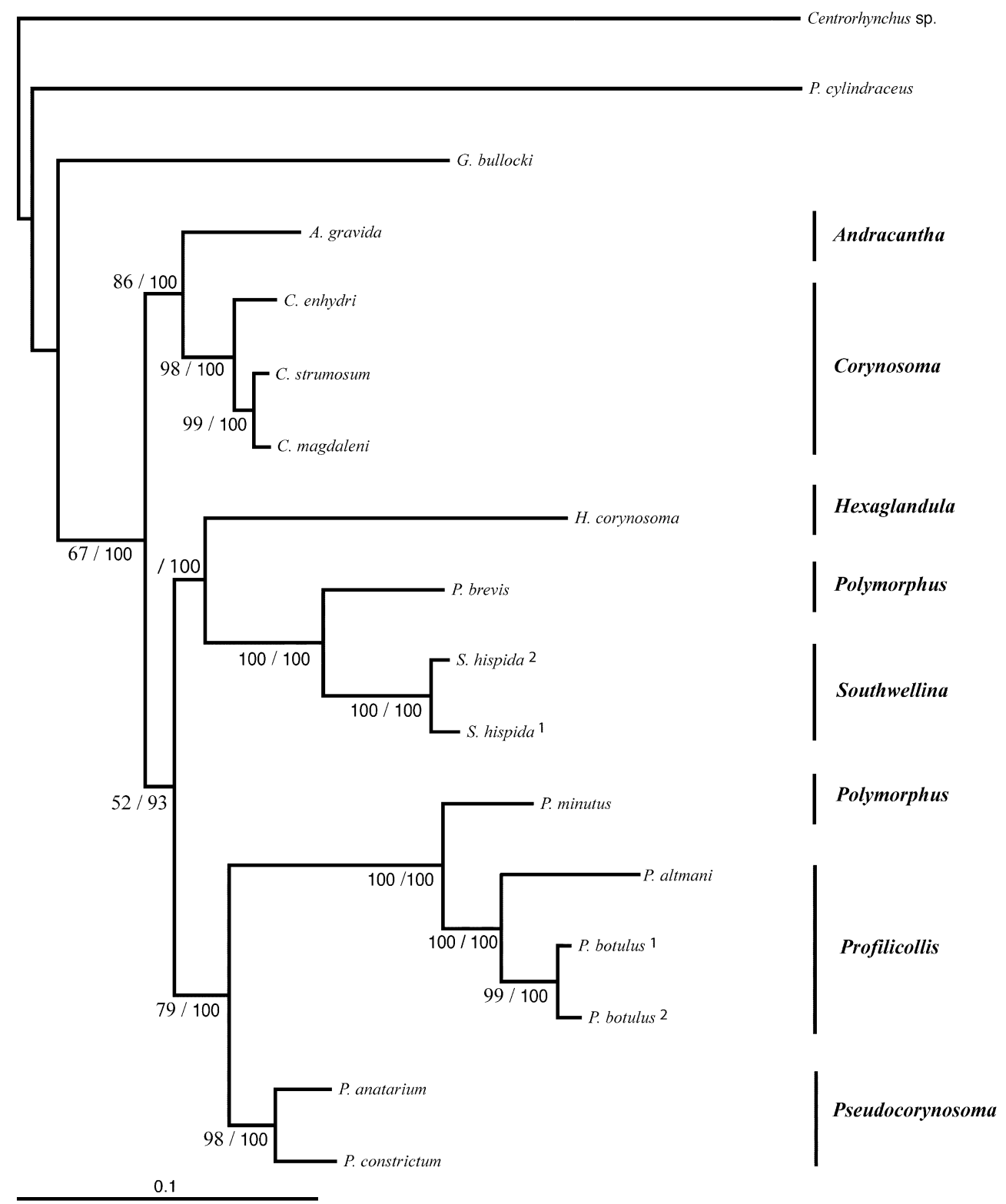

FIgURE 4. ML and Bayesian trees inferred from the concatenated SSU + LSU + cox 1 dataset. Branch lengths are scaled to the expected number of substitutions per site $(-\ln$ of $21,129.49)$ and are based on the likelihood analysis. Numbers near internal nodes show ML bootstrap clade frequencies and Bayesian posterior probabilities, respectively (ML/Bayesian).

of Spain to MGV. FJA benefits from a "Ramón y Cajal" contract from the MEC.

\section{LITERATURE CITED}

AmERICAN ORnithologists' Union (AOU). 1998. Check-list of North American birds, 7th ed. American Ornithologists' Union, Washington, D.C., 198 p.

Amin, O. M. 1992. Review of the genus Polymorphus Lühe, 1904 (Acanthocephala: Polymorphidae), with the synonymization of Hexaglandula Petrochenko, 1950, and Subcorynosoma Hoklova, 1967, and a key to the species. Qatar University Science Journal 12: $115-123$.

Aznar, F. J., A. O. Bush, And J. A. Raga. 1999. Polymorphus arctocephali Smales, 1986, a synonym of Corynosoma cetaceum Johnston and Best, 1942 (Acanthocephala: Polymorphidae). Systematic Parasitology 44: 59-70.

, G. Perez-Ponce de León, And J. A. Raga. 2006. Status of
Corynosoma (Acanthocephala: Polymorphidae) based on anatomical, ecological and phylogenetic evidence, with the erection of Pseudocorynosoma n. gen. Journal of Parasitology 92: 548-564.

Belopolskaja, M. M. 1958. The parasite fauna of birds of the Sudzukhinsk Reserve (Primore). II. Acanthocephala. Parazitologicheskii Sbornik 18: $304-320$.

FARIAS, J. D., AND A. G. CANARIS. 1986. Gastrointestinal helminths of the Mexican duck, Anas platyrhynchus diazi, from north central México and Southwestern USA. Journal of Wildlife Diseases 22: $51-54$.

FelsensteIn, J. 1999. PHYLIP (phylogeny inference package), version 3.572. University of Washington, Seattle, Washington.

Folmer, O., M. Black, W. Hoeh, R. Lutz, and R. VRijenhoek. 1994 DNA primers for the amplification of mitochondrial cytochrome $\mathrm{c}$ oxidase subunit I from diverse metazoan invertebrates. Molecular Marine Biology and Biotechnology 3: 294-299.

García-Varela, M., F. J. Aznar, G. Pérez Ponce de León, D. Piñero, AND J. P. LACLETTE. 2005. Molecular phylogeny of Corynosoma 
Lühe, 1904 (Acanthocephala), based on 5.8S and internal transcribed spacer sequences. Journal of Parasitology 91: 345-352. -, AND S. A. NADLER. 2005. Phylogenetic relationships of palaeacanthocephala (Acanthocephala) inferred from SSU and LSU rDNA gene sequences. Journal of Parasitology 91: 1401-1409.

, AND G. PÉREZ-PonCE DE LEÓN. 2008. Validating the systematic position of Profilicollis Meyer, 1931 and Hexaglandula Petrochenko, 1950 (Acanthocephala: Polymorphidae) using cytochrome c oxidase (cox 1). Journal of Parasitology 94: 212-217.

Garey, J. R., T. J. Near, M. R. Nonnemacher, and S. A. Nadler. 1996. Molecular evidence for Acanthocephala as a subtaxon of Rotifera. Journal of Molecular Evolution 43: 287-292.

Golvan, Y. J. 1959. Acanthocéphales du genre Corynosoma Lühe, 1904, parasites de mammifères d'Alaska et de Midway. Annales de Parasitologie Humaine et Comparée 34: 288-321.

HoberG, E. P. 1986. Aspects of ecology and biogeography of Acanthocephala in Antarctic seabirds. Annales de Parasitologie Humaine et Comparée 61: 199-214.

-, AND A. ADAMS. 2000. Phylogeny, history and biodiversity: Understanding fauna structural and biogeography in the marine realm. Bulletin of the Scandinavian Society of Parasitology 10: 19-37.

Howell, S. N. G., AND S. WebB. 1995. A guide to the birds of México and Northern Central America. Oxford University Press, New York, $851 \mathrm{p}$.

Huelsenbeck, J. P., And F. Ronquist. 2001. MrBayes: Bayesian inference of phylogeny. Version 3.0b4. Distributed by the author. Department of Biology, University of Rochester, Rochester, New York

Loytynoja, A., And M. C. Milinkovitch. 2003. A hidden Markov model for progressive multiple alignment. Bioinformatics 19: 15051513.

Monteiro, M. C, J. F. R. Amato, and S. B. Amato. 2006. A new species of Andracantha Schmidt (Acanthocephala, Polymorphidae) parasite of Neotropical cormorants, Phalacrocorax brasilianus (Gmelin) (Aves, Phalacrocoracidae) from Southern Brazil. Revista Brasileira de Zoologia 3: 807-812.

Nickol, B. B., D. W. T. Crompton, and D. W. Searle. 1999. Reintroduction of Profilicollis Meyer, 1931, as a genus in Acanthocephala: Significance of the intermediate host. Journal of Parasitology 85: 716-718.

, R. W. HEARD, AND N. F. SMith. 2002. Acanthocephalans from crabs in the southeastern US, with the first intermediate hosts known for Arhythmorhynchus frassoni and Hexaglandula corynosoma. Journal of Parasitology 88: 79-83.

PetrochenKo, V. I. 1958. Acanthocephala of domestic and wild ani- mals. Volumen II. Moscow: Izdatel'stvo Akademii Nauk SSSR, Vsesoyuznoe Obshchestvo Gel'mintologov, Moscow, Russia, 478 p.

Pichelin, S., A. M. Kuris, And R. GuRney. 1998. Morphological and biological notes on Polymorphus (Profilicollis) sphaerocephalus and Corynosoma stanleyi (Polymorphidae: Acanthocephala). Journal of Parasitology 84: 798-801.

Podesta, R. B., AND J. C. Holmes. 1970. The life cycles of three polymorphids (Acanthocephala) occurring as juveniles in Hyalella azteca (Amphipoda) at Cooking Lake, Alberta. Journal of Parasitology 56: $1118-1123$.

Posada, D., AND K. A. CRandall. 1988. Modeltest: Testing the model of DNA substitution. Bioinformatics 9: 817-818.

Rodríguez, F., J. F. Oliver, A. Marin, And J. R. Medina. 1990. The general stochastic model of nucleotide substitution. Journal of Theoretical Biology 142: 817-818.

Sanderson, M. J., M. J. Donoghue, W. Piel, and T. Eriksson. 1994. TreeBASE: A prototype database of phylogeny analyses and an interactive tool for browsing the phylogeny of life. American Journal of Botany 81: 183.

SchmidT, G. D. 1973. Resurrection of Southwellina Witenberg, 1932, with a description of Southwellina dimorpha sp. n., a key to genera in Polymorphida (Acanthocephala). Journal of Parasitology 59: 299-305.

1975. Andracantha a new genus of Acanthocephala (Polymorphidae) from fish-eating birds, with descriptions of three species. Journal of Parasitology 61: 615-620.

. 1985. Development and life cycles. In Biology of Acanthocephala, B. B. Nickol, and D. W. T. Crompton (eds.). Cambridge University Press, Cambridge, U.K., p. 273-286.

Shimodaira, H., AND M. Hasegawa. 1999. Multiple comparisons of log-likelihoods with applications to phylogenetic inference. Molecular Biology and Evolution 16: 1114-1116.

SwOFFORD, D. L. 2002. PAUP 4.0b10. Phylogenetic analysis using parsimony (and other methods). Sinauer Associates, Sunderland, Massachusetts.

Templeton, A. R. 1983. Phylogenetic inference from restriction endonuclease cleavage site maps with particular reference to the humans and apes. Evolution 37: 221-224.

Van Cleave, H. J. 1945. The Acanthocephalan genus Corynosoma I. The species found in water birds of North America. Journal of Parasitology 25: 332-340.

Yamaguti, S. 1963. Systema helminthum. Vol. V, Acanthocephala. Interscience Publishers, New York, New York, 423 p.

YANG, Z. 1994. Estimating the patterns of nucleotide substitution. Journal of Molecular Evolution 39: 105-111.

ZDZITOWIECKI, K. 1985. Acanthocephalans of birds from South Shetlands (Antarctic). Acta Parasitologica Polonica 31: 117-123. 